\title{
SSG-Geschenke - Ideen und Empfehlungen 2014
}

\section{Patienteninformation}

Haben Sie einen Tipp für mich, was wir unserem stotternden Kind schenken können? Weißt Du, was ich meiner Kollegin zu Ihrer neuen logopädischen Praxis schenken kann? Wissen Sie noch gute Bücher, die wir in unserer Kindergartengruppe anschaffen sollten? So oder so ähnlich werden wir häufig nach Empfehlungen aus logopädischer Sicht gefragt. Das Team der Schule für Logopädie der MHH hat für Sie dazu auch dieses Jahr wieder ein paar Anregungen und Antworten zusammengestellt.

\section{Bücher \\ „Was hörst du hier?“ Bauernhoftiere}

Anna Räuber, Dorothea Ackroyd

2013, Ars edition

$9,99 €$

ISBN 978-3-8458-0195-7

Kleine Tiere

Andrea Gerlich, Dorothea Ackroyd

2013, Ars edition

$9,99 €$

ISBN 978-3-8458-0196-4

\section{Kai ist (k)ein blöder Name} Anina Ramann

2014, Natke-Verlag

$7,90 €$

ISBN 978-3-936640-19-9

\section{Kommentar}

Ein erstes Bilderbuch für Kinder ab 1,5 Jahren, das zum Hinhören und Imitieren einlädt. Zu den einzelnen Situationsbildern werden kurze Informationen im Text gegeben und einfache Suchaufgaben gestellt („Wo ist..."). Der Clou sind kleine Buttons, die das Kind drücken kann, um dann den entsprechenden Tierlaut zu hören.

\section{Ein siebenjähriger stotternder Junge} freundet sich mit einem mutigen hörgeschädigten Jungen an und bekommt Ideen für einen selbstbewussten Umgang mit einem Handicap. Ansprechend geschriebenes und illustriertes Buch, das einen guten Aufhänger liefern kann, um mit einem stotternden Kind ins Gespräch zu kommen.

\section{Die Maus, das Monster und ich} Pat Palmer

3. Auflage 2013, mebes \& noack ISBN 978-3-92779620-1

$14,50 €$

Ausgehend von einem Monster, das seine Bedürfnisse herauspoltert und einer Maus, die sich nicht traut, ihre eigenen Wünsche zu formulieren, vermittelt das Buch mit vielen Anregungen zum Schreiben, Malen und Spielen, wie soziale Fähigkeiten gefördert und Selbstbewusstsein auffür Kinder ab 7-8 Jahren.

\section{Leitlinien der Stimmtherapie}

Marianne Spiecker-Henke

2. vollständig überarbeitete und erweiterte Auflage 2014, Thieme $69,99 €$

ISBN 978-3-13103162-4 Dies ist die in den Fachkreisen schon lange erwartete neue und überarbeitete Ausgabe eines stimmtherapeutischen Standardwerkes. gebaut werden können. Ein Buch
Weitere Ideen

CD: Geräusche-Lotto

Nr. 549243, Dusyma-Verlag $47,95 €$

\section{Kommentar}

Auf einer $C D$ finden sich zu den Themenfeldern Strand, Garten, Küche, Park, Straße und Wald typische Geräusche, die Kinder ab 4 Jahren erkennen und heraushören sollen. So kann sowohl das differenzierte Hörvermögen als auch die Konzentrationsfähigkeit und visuelle Differenzierung gefördert werden.

\section{CD: Geräusche im Zoo}

Carola Preuß, Klaus Ruge 2000 , Verlag an der Ruhe $16,95 €$

ISBN 978-3-86072482-8

CD: Leise Alltagsgeräusche Carola Preuß, Klaus Ruge 2009, Verlag an der Ruhe $16,95 €$ ISBN 978-3-83460497-2

\section{Spiel: Teekesselchen}

Nr. 2587, Haba

29 Bildkarten u. 3 Blankokarten

Ca. $20 €$

\section{Trainingsgerät: Kettler Air} Stepper K07350-072

Erhältlich in Sportgeschäften oder im Sportartikelversand Ca. $20 €$

Auf einer CD finden sich die Stimmen von 28 verschiedenen Zootieren, die auf Bildkarten zu finden sind, was z.B. beim Piranha sehr lustig ist.

Für das genaue Hinhören ist die CD zu den leisen Alltagsgeräuschen (30 Bildkarten und Geräusche) bestens zu empfehlen. So kann sowohl das differenzierte Hörvermögen als auch die Konzentrationsfähigkeit und visuelle Differenzierung gefördert werden.

Ein Ratespiel für Kinder ab 6 Jahren, das mit 4 und mehr Personen gespielt werden kann. Hierbei sind die Spieler einerseits gefordert, einen Begriff zu umschreiben, als auch allein aufgrund von Hinweisen (z.B. zum Aussehen oder Gebrauch) zu erraten. Es sind also sprachliches "Geschick“ sowie Weltwissen im Spiel um die klanggleichen Teekesselchen gefragt.

Eignet sich weniger zum professionellen Steppen, kann jedoch an allen Orten eingesetzt werden, an denen man längere Zeit flexibel aufrecht steht. Durch die erzielte bewegliche Aufrichtung ist der Stepper ein gut geeignetes Gerät für die Stimmtherapie. Auf einem Stuhl erfüllt der Stepper die Funktion eines Keilkissens, wobei das Steißbein angenehm entlastet wird.

Birte Ripken für das Team der Schule für Logopädie der MHH, Hannover

überreicht durch Thieme und 